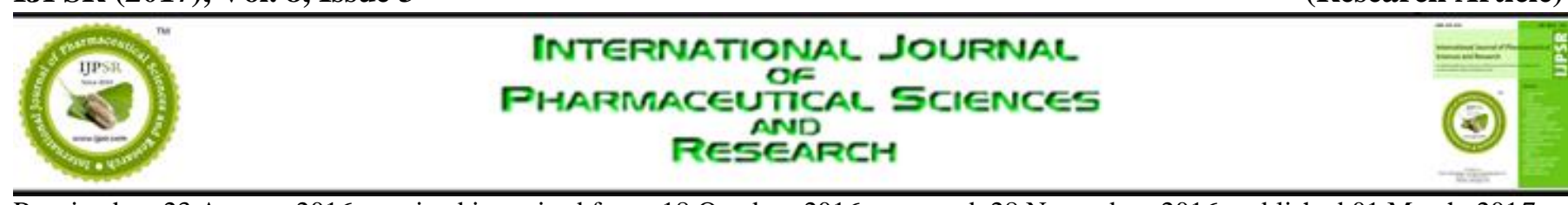

Received on 23 August, 2016; received in revised form, 18 October, 2016; accepted, 28 November, 2016; published 01 March, 2017

\title{
FORMULATION AND EVALUATION OF INDAPAMIDE SUSTAINED RELEASE MATRIX TABLETS
}

\section{Rajesh Babu* and Syeda Rana Nikhat}

Department of Pharmaceutics, MESCO College of Pharmacy, Hyderabad, Telangana, India.

Keywords:

Sustained release matrix tablets, Indapamide, HPMC K 100, Preformulations and wet granulation.

\section{Correspondence to Author:}

V. Rajesh Babu

Sr. Assistant Professor MESCO College of Pharmacy Mustaidpura, Karwan Road Hyderabad-06, Telangana, India.

E-mail: rajeshbabuvemula@gmail.com

\begin{abstract}
The study was undertaken with an aim to formulate antihypertensive agents as sustained release matrix tablets. The literature review showed that Indapamide is an anti hypertensive / diuretics in SR dosage form $50 \%$ of drug is released between $5-14 \mathrm{hrs}$ and $20-80 \mathrm{ng} / \mathrm{ml}$ blood level is obtained for $24 \mathrm{hrs}$ and SR form permits uniform and constant blood level after absorption of galenic form by oral route up to now it is available as IR with an dose of $2.5 \mathrm{mg} /$ day which results in considerable blood peaks, it is formulated as SR form to avoid and maintain constant blood level and to maintain better theraupetic index. In the present study, HPMC was found to play a great role in controlling release of drug Indapamide from the matrix system. Incorporation of HPMC K 100 M CR as release controlling polymer in extra granular fraction was found helpful in restoring the original and still closer release profile.
\end{abstract}

INTRODUCTION: Indapamide is the first of a new class of antihypertensive/diuretics, the indolines. It has been reported that the oral administration of $2.5 \mathrm{mg}$ (two $1.25 \mathrm{mg}$ tablets) of Indapamide to male subjects produced peak concentrations of approximately $115 \mathrm{ng} / \mathrm{mL}$ of the drug in blood within two hours. It has been reported that the oral administration of $5 \mathrm{mg}$ (two $2.5 \mathrm{mg}$ tablets) of Indapamide to healthy male subjects produced peak concentrations of approximately $260 \mathrm{ng} / \mathrm{mL}$ of the drug in the blood within two hours. A minimum of $70 \%$ of a single oral dose is eliminated by the kidneys and an additional $23 \%$ by the gastrointestinal tract, probably including the biliary route.

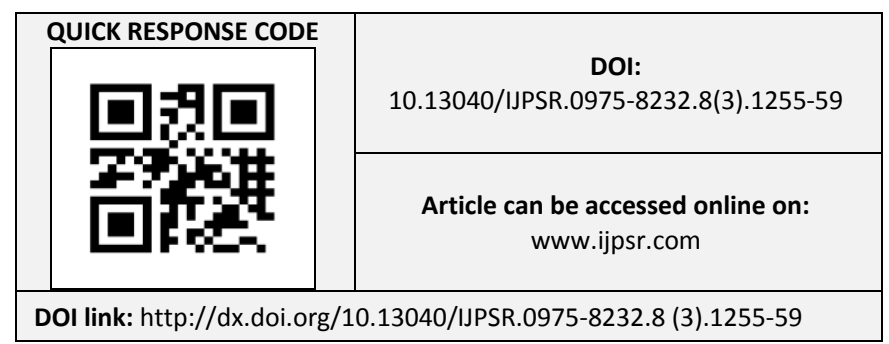

The half-life of Indapamide in whole blood is approximately 14 hours $1,2,3$. Indapamide is preferentially and reversibly taken up by the erythrocytes in the peripheral blood. The whole blood/plasma ratio is approximately $6: 1$ at the time of peak concentration and decreases to $3.5: 1$ at eight hours. From 71 to $79 \%$ of the indapamide in plasma is reversibly bound to plasma proteins.

Indapamide is an extensively metabolized drug with only about $7 \%$ of the total dose administered, recovered in the urine a pharmacokinetic $\mathrm{s}$ unchanged drug during the first 48 hours after administration. The urinary pharmacokinetic elimination of ${ }^{14} \mathrm{C}$-labeled Indapamide and metabolites is biphasic with a terminal half-life of excretion of total radioactivity of 26 hours.

In a parallel design double-blind, placebo controlled trial in hypertension, daily doses of indapamide between $1.25 \mathrm{mg}$ and $10 \mathrm{mg}$ produced dose-related antihypertensive effects. Doses of 5 and $10 \mathrm{mg}$ were not distinguishable from each other although each was differentiated from 
placebo and $1.25 \mathrm{mg}$ Indapamide. At daily doses of $1.25 \mathrm{mg}, 5 \mathrm{mg}$ and $10 \mathrm{mg}$, a mean decrease of serum potassium of $0.28,0.61$ and $0.76 \mathrm{mEq} / \mathrm{L}$, respectively, were observed and uric acid increased by about $0.69 \mathrm{mg} / 100 \mathrm{ml}^{6,7,8}$.

MATERIALS AND METHODS: Indapamide was obtained as a gift sample from Dr Reddy's Laboratories Ltd, Hyderabad, Telangana state. Micro crystalline cellulose $\mathrm{pH}$ 102, Micro crystalline cellulose pH 114, Mannitol, Iso propyl alcohol, HPC-LF, Zinc stearate, HPMC K 100 M, Ly coat, Aerosil.

Method of preparaion of tablets: Wet granulation is a process of dry mixing, wet mixing, and particle size enlargement, and is a process of particle attachment (agglomeration). It consists of six steps: Dry mixing, wet mixing, Milling of the wetted mass, Drying, Milling and sizing of the dried mass, final blending and coating.

TABLE 1: COMPOSITION OF DIFFERENT BATCHES OF INDAPAMIDE TABLETS:

\begin{tabular}{cccccccccc}
\hline Ingredients (mg/tab) & F-1 & F-2 & F-3 & F-4 & F-5 & F-6 & F-7 & F-8 \\
\hline Indapamide & 1.5 & 1.5 & 1.5 & 1.5 & 1.5 & 1.5 & 1.5 & 1.5 \\
Mannitol & 45.00 & 24.00 & - & 45.00 & 24.00 & 45.00 & 24.00 & 45.00 \\
HPMC K 100 M & 7.50 & - & - & - & - & - & & - \\
HPC - LF & 0.75 & 0.75 & 0.75 & 0.75 & 0.75 & 0.75 & 1.1 & 0.75 \\
Zinc stearate & 0.25 & 0.25 & 0.25 & 0.25 & 0.25 & 0.25 & 0.25 & 0.25 \\
Purified water & q.s & q.s & q.s & q.s & q.s & q.s & q.s & q.s \\
MCC 114 & - & 21.00 & 23.00 & - & - & - & - & - \\
HPMC KM/15M/100M & - & 7.50 & 4.00 & 8.00 & 38.5 & 33.0 & 33.0 & 11.0 \\
Aerosil & - & - & - & - & - & - & 0.25 & - \\
\hline
\end{tabular}

Characterization of the tablets:

- Average Weight: Weigh accurately 20Tablets and calculate the average weight.

- Hardness: Determine the hardness of 10Tablets, using a suitable calibrated hardness tester.

- Thickness: Determine the thickness of 10Tablets, using a Vernier calipers.

- Friability: Weigh accurately 20 tablets and place them in the friability test apparatus. Adjust the timer to 4 minutes. Operate the apparatus at $25+1 \mathrm{rpm}$ and observe the tablets while rotating. No tablets should stick to the walls of the apparatus. Take the tablets out and observe. No capping should be observed. Weigh the tablets, after dedusting excess powder from their surface.

- Uniformity of weight: Weigh accurately 20 tablets and calculate the average weight. Then weigh the 20 tablets individually. Find out the tablets having the highest weight and the tablets having the lowest weight, in the above 20 tablets.

\section{- Dissolution by HPLC:}

Apparatus: USP Apparatus II

RPM: 50

Medium: 900ml pH 6.8 Phosphate buffer

Temp: $37+0.5^{\circ} \mathrm{C}$

Sampling Interval: 1, 4, 8 ,12, 16, 20 , 24 hours

Preparation of $0.2 \mathrm{M}$ monobasic potassium phosphate solution: Dissolve $27.22 \mathrm{gms}$ of monobasic potassium phosphate in water dilute with water to $1000 \mathrm{ml}$,

Preparation of $0.2 \mathrm{M}$ sodium hydroxide solution: Dissolve sodium hydroxide in water and dilute to $1000 \mathrm{ml}$ Heat the medium.

Preparation of $6.8 \mathrm{pH}$ phosphate buffer: Place $250 \mathrm{ml}$ of $0.2 \mathrm{M}$ monobasic potassium phosphate solution and $112 \mathrm{ml}$ of $0.2 \mathrm{M}$ sodium hydroxide in $1000 \mathrm{ml}$ volumetric flask and dilute to $1000 \mathrm{ml}$ with water .

\section{Chromatographic Conditions:}

Buffer : Dissolve 0.05M 8.71gms of dipotassium hydrogen phosphate in $1000 \mathrm{ml}$ of Milli- Q - water and mix and add $1 \mathrm{ml}$ of Triethylamine adjust $\mathrm{pH}$ to 3.60 with ortho phosphoric acid filter above solution through $0.45 \mathrm{um}$ filter. 
Mobile Phase : Acetonitrile and buffer in ratio 40:60 (degas and sonicate for $10 \mathrm{mins}$ )5

Column : Intersil ODS 3V $150 \times 4.6 \mathrm{~mm}, 4 \mu$

Flow rate $: 1.0 \mathrm{ml} / \mathrm{minute}$

Wave length : 240nm

Temperature : 65

Load $\quad: 50 \mu l$

Run time : 10.minutes

Standard Preparation: Weigh and place 52mg of standard into $250 \mathrm{ml}$ volumetric flask. Dissolve and dilute with Methanol. Pipette $2 \mathrm{ml}$ of solution in to $250 \mathrm{ml}$ volumetric flask make up vol with medium.
Sample preparation: Transfer 6 tablets individually in six dissolution flasks containing $900 \mathrm{ml}$ of the medium that has been equilibrated to $37^{\circ} \mathrm{C} \pm 0.5^{\circ} \mathrm{C}$. Take care to exclude air bubbles from the surface of the tablets, start the apparatus immediately. Collect the sample after the specified time, withdraw sample from a zone midway between the surface of the medium and top of the rotating blade and not less than $1 \mathrm{~cm}$ from the vessel wall and filter through $0.45 \mu$ membrane filter by discarding the $5 \mathrm{ml}$.

Procedure: Separately inject the standard preparation into the liquid chromatography and record the area due to major peaks.

\section{RESULTS and DISCUSSION:}

TABLE 2: ???

\begin{tabular}{cccccccc}
\hline $\begin{array}{c}\text { Formula } \\
\text { (Trials) }\end{array}$ & $\begin{array}{c}\text { Bulk } \\
\text { density }\end{array}$ & $\begin{array}{c}\text { Tapped } \\
\text { density }\end{array}$ & $\begin{array}{c}\text { Carr's } \\
\text { Index }(\boldsymbol{\%})\end{array}$ & $\begin{array}{c}\text { Diameter } \\
(\mathbf{m m})\end{array}$ & $\begin{array}{c}\text { Thickness } \\
(\mathbf{m m})\end{array}$ & $\begin{array}{c}\text { Friability } \\
(\boldsymbol{\%})\end{array}$ & $\begin{array}{c}\text { Content } \\
\text { uniformity }(\boldsymbol{\%})\end{array}$ \\
\hline F-1 & 0.52 & 0.69 & 25.0 & $7.0 \pm 0.0$ & $4.8 \pm 0.0$ & 0.12 & $95.0 \pm 0.9$ \\
F-2 & 0.49 & 0.67 & 24.0 & $7.1 \pm 0.0$ & $4.6 \pm 0.0$ & 0.15 & $93.0 \pm 0.9$ \\
F-3 & 0.52 & 0.59 & 25.5 & $6.9 \pm 0.0$ & $4.9 \pm 0.0$ & 0.13 & $98.0 \pm 0.9$ \\
F-4 & 0.53 & 0.62 & 23.5 & $6.5 \pm 0.0$ & $4.3 \pm 0.0$ & 0.18 & $97.0 \pm 0.9$ \\
F-5 & 0.50 & 0.70 & 27.5 & $7.3 \pm 0.0$ & $4.7 \pm 0.0$ & 0.16 & $96.0 \pm 0.9$ \\
F-6 & 0.52 & 0.52 & 25.5 & $7.8 \pm 0.0$ & $4.6 \pm 0.0$ & 0.15 & $95.0 \pm 0.9$ \\
F-7 & 0.55 & 0.65 & 23.5 & $6.9 \pm 0.0$ & $4.1 \pm 0.0$ & 0.12 & $94.0 \pm 0.9$ \\
F-8 & 0.61 & 0.58 & 28.5 & $7.7 \pm 0.0$ & $4.5 \pm 0.0$ & 0.11 & $96.0 \pm 0.9$ \\
\hline
\end{tabular}

Based on the preformulation data, HPMC $\mathrm{K} 100 \mathrm{M}$ was taken as release controlling polymer, mannitol and MCC114 as diluents, HPC-LF as binder, aerosil as glidant, zinc stearate as lubricant.

In Trial 1, HPMC K100M was used as release controlling polymer and mannitol as diluent, this trail is taken to check various problems in processing of tablets, the tyablets which are processed passed all the in process quality control tests (thickness, friability, hardness, weight variation,). But the flow of dried granules should be improved and compressibility of granules also to be improved.

In Trial 2, Mannitol and MCC114 are combinedly used as diluents to increase flow and compressibility of dried granules, and HPMC K (4M,15M,100M,) are used as release controlling polymer to check for their release profile, the tablets with HPMC
$\mathrm{K} 100 \mathrm{M}$ are showing retarded release.

In Trial 3, 4 HPMC K100M taken as release conrolling polymer in $(7 \%, 14 \%, 20 \%)$ concentration to check for there release profile, tablets with higher concentration of polymer showing more retarded release.

In Trial 5, 6 HPMC K $100 \mathrm{M}$ taken as release controlling polymer in $(60 \%, 70 \%$, concentration to check for there release profile, tablets showing release profile similar to that of innovator product but during processing of tablets hard granules are formed which are very difficult to mill and sift. So the process to be optimized.

In Trial 7, binding solution water was replaced with alcohol and water in ratio of (9:1) respectively, no hard granules are observed but tablets dissolved totally in $0.1 \mathrm{~N}$ $\mathrm{Hcl}$ with in 1 hour. 
In Trial 8, HPMC K100M (CR) is taken as release controlling polymer and used in extra granulation part, the granules which are formed are soft and no difficulties observed in sifting, the tablets showing release profile is $98 \%$.

TABLE 3: DISSOLUTION PROFILE FOR INDAPAMIDE TABLETS

\begin{tabular}{c|cccccccc}
\hline \multirow{2}{*}{ Time in Hours } & \multicolumn{10}{c}{ \% Drug Release } \\
\cline { 2 - 9 } & F-1 & F-2 & F-3 & F-4 & F-5 & F-6 & F-7 & F-8 \\
\hline 1 & 10 & 32 & 20 & 3 & 11 & 20 & 3 & 14 \\
4 & 49 & 52 & 9 & 16 & 22 & 38 & 16 & 20 \\
8 & 53 & 54 & 33 & 30 & 35 & 54 & 30 & 52 \\
12 & 66 & 64 & 55 & 44 & 46 & 68 & 44 & 55 \\
16 & 71 & 72 & 69 & 55 & 54 & 84 & 55 & 64 \\
20 & 75 & 76 & 75 & 66 & 62 & 97 & 66 & 68 \\
24 & 76 & 79 & 81 & 76 & 69 & 98 & 76 & 73 \\
\hline
\end{tabular}

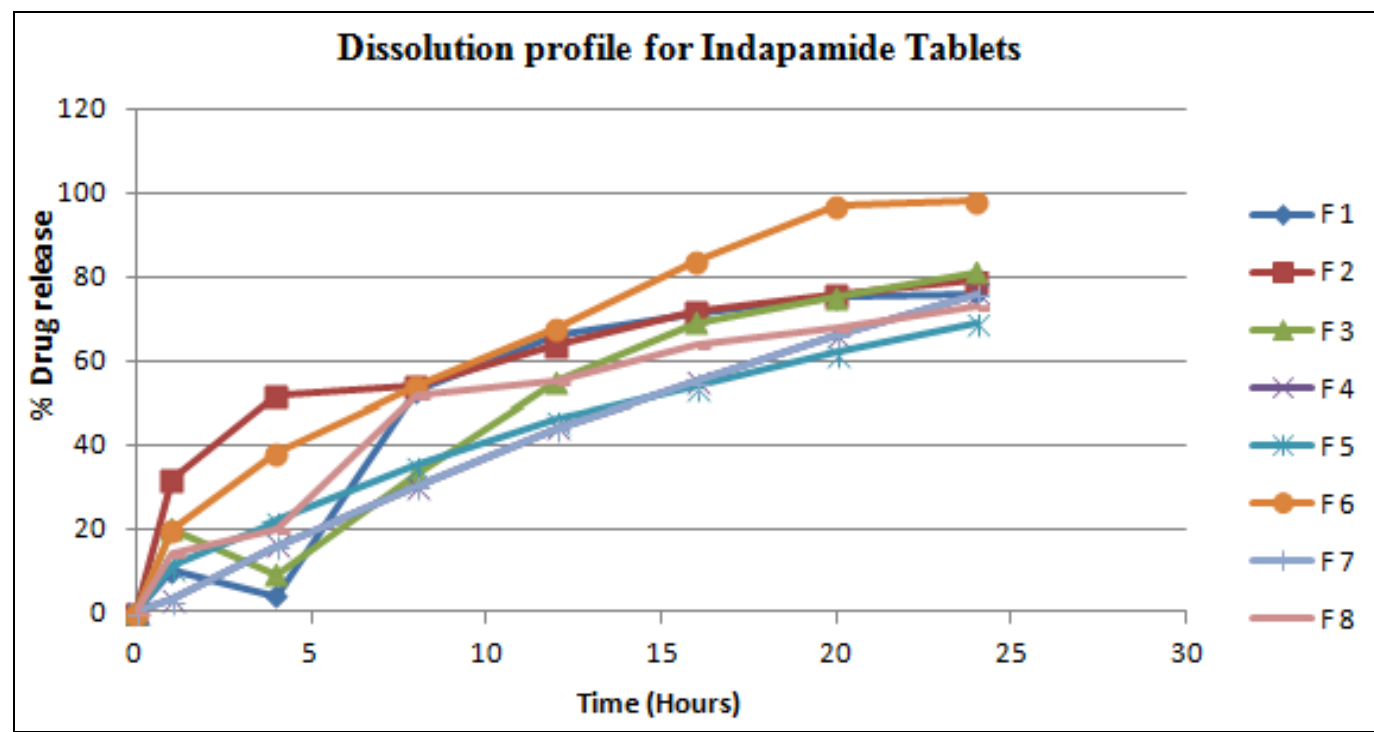

FIG. 1: DISSOLUTION PROFILE FOR INDAPAMIDE TABLETS

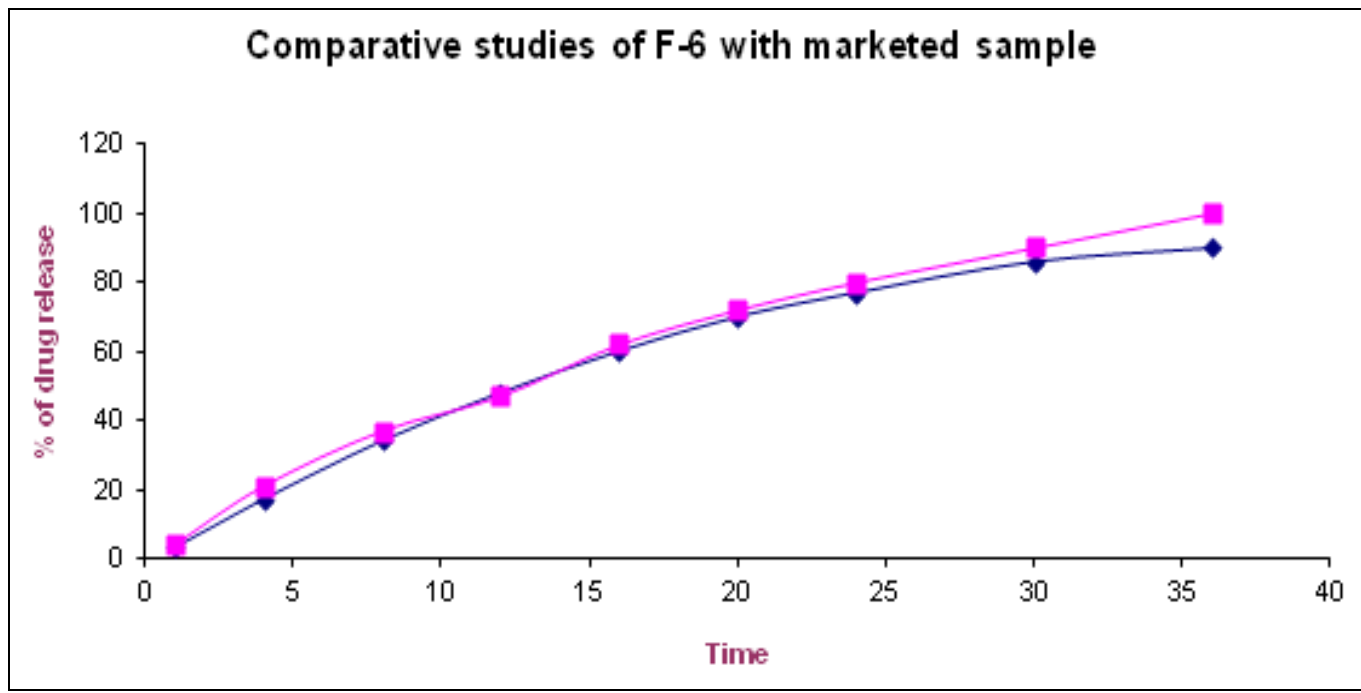

FIG. 2: COMPARATIVE STUDIES OF F-6 WITH MARKETED SAMPLE

SUMMARY AND CONCLUSION: In the present study, HPMC was found to play a great role in controlling release of drug indapamide from the matrix system. Incorporation of HPMC K 100 M $\mathrm{CR}$ as release controlling polymer in extra granular fraction was found helpful in restoring the original and still closer release profile. Preformulation study and drug excipients compatibility study was done initially and results directed the further course of formulation. With the data from literature review, 
Preformulation and Excipients compatibility study Prototype formulation trials were started. Wet granulation process was used for both the layers formulation by using the RMG Granules were evaluated for tests such as LOD, Bulk density, Tapped density, Compressibility Index and Hausner ratio \& sieve analysis before being punched as tablets. Tablets were tested for weight variation, thickness, hardness and friability, In-vitro dissolution tests were performed and f2 values were calculated. Dissolution profile matched with innovators product and $\mathrm{f} 2$ value was satisfactory. Accordingly, it can be concluded that the final formulation is a robust one and the performance is less likely to be affected by the various factors studied. An excellent in vitro -in vivo correlation is expected as evident from degree of similarity found in gradient dissolution in different media and release kinetics with respect to the reference listed drug products and as comparing with the commercial drugs also shows good dissolution studies.

ACKNOWLEDGEMENT: The authors are thankful to Dr. Mir Wajahath Ali, Convener MESCO College of Pharmacy for his constant encouragement and kind support.
1. Yeole P.G., Galgatte U.C., Babla I.B. and Nakhat P.D, Design and evaluation of Xanthan gum based SR matrix tablets of Diclofenac Sodium, Indian Journal of Pharmaceutical Sciences, 2006, 68(2): 185

2. Pandey V.P., Manavalan R, Syed Munawar Hessian and Srinivasa rao P.L., Formulation and development of naproxen conventional tablets, THE INDIAN PHARMACIST-JANUARY, 2007: 85.

3. Venkatesh, Nath B.S, HPMC as wicking agent in Matrix tablets of Cetyl alcohol, Indian drugs 1999, Vol 36: 720.

4. Thilak Kumar M., Srinivas G., HPMC based Matrix tablets of Atenolol and Cisapride. Indian Journal of Pharmaceutical Sciences 2005, Vol 67: 414

5. Dhuikhel., effect of Drug Solubility and polymer viscosity on invitro drug release from HPMC matrix tablets, INDIAN DRUGS, 2005: 42

6. Lawrence X.Yu, Christopher D. Elison, Dale P. Conner, Larry J. Lesko, and Ajaz S. Hussain, Influence of Drug Release Properties of Conventional Solid Dosage Forms on the Systemic Exposure of Highly Soluble Drugs, AAPS Pharm Sci. 2001; 3(3): 24

7. Rantanen J, Rasanen E, Tenhunen J, Kansakoski M.; Mannermaa J.; Yliruusi J.; An evaluation of particle size and binder effects, Eur.j.pharm.biopharm.2000, vol.50: 271-2762

8. Becker D., Rigassi T., Bauer- Brandla A., Effectiveness of Binders Using Wet granulation. Drug development and industrial pharmacy, 1997, Vol 51: 356

9. Pavol Rajnaik, Frantisek Stepanek, Christopher Mancinelli, Rey Chern, Leon Farber, and Brian Hill, Experimental study of wet granulation in fluidized bed: Impact of the binder properties on the granule morphology, INIST-CNRS, 2006.

10. Chowdary K.P.R, Pregelatinized starch: A potential pharmaceutical excipient. The eastern pharmacist, April 2000: 33 .

\section{REFERENCES:}

How to cite this article:

Babu VR and Nikhat SR: Formulation and evaluation of indapamide sustained release matrix tablets. Int J Pharm Sci Res 2017; 8(3): 1255-59.doi: 10.13040/IJPSR.0975-8232.8(3).1255-59.

All @ 2013 are reserved by International Journal of Pharmaceutical Sciences and Research. This Journal licensed under a Creative Commons Attribution-NonCommercial-ShareAlike 3.0 Unported License.

This article can be downloaded to ANDROID OS based mobile. Scan QR Code using Code/Bar Scanner from your mobile. (Scanners are available on Google Playstore) 